Article

\title{
Tools for Sustainable Fashion Design: An Analysis of Their Fitness for Purpose
}

\author{
Anika Kozlowski ${ }^{1, * \mathbb{D}}$, Michal Bardecki ${ }^{2}$ and Cory Searcy ${ }^{3}$ \\ 1 School of Fashion, Ryerson University, Toronto, ON M5B 2K3, Canada \\ 2 Department of Geography and Environmental Studies, Ryerson University, Toronto, ON M5B 2K3, Canada \\ 3 Yeates School of Graduate Studies, Ryerson University, Toronto, ON M5B 2K3, Canada \\ * Correspondence: a2kozlow@ryerson.ca
}

Received: 6 May 2019; Accepted: 21 June 2019; Published: 28 June 2019

\begin{abstract}
Understanding the complexity of sustainable fashion issues can be overwhelming and a barrier for fashion designers. A number of tools for sustainable fashion design have been developed to aid designers in the integration of sustainability into their design practices. We analyze these to determine their fitness for purpose. Among them, three categories (archetypes) of tools are identified: Universal, Participatory, and Assessment. We propose an innovation framework and a five-dimensional model of sustainability specific to fashion to facilitate the analysis of the tools. Using the archetype categorization may facilitate designers in identifying the most appropriate type of tool for a specific circumstance, depending on context and need.
\end{abstract}

Keywords: sustainability; sustainable fashion; fashion design; sustainable design; design tools; design practice

\section{Introduction}

There is widespread recognition that the fashion industry's current practices have adverse environmental, economic and social impacts [1-4]. A growing body of literature, resources and tools supports the transition to sustainable practices. Fashion brands around the world are beginning to implement sustainability strategies and large companies, such as Kering, Zara, Nike, and H\&M, regularly issue publicly-available reports describing their sustainability activities. Likewise, many fashion micro- and small enterprises (MSEs) are adopting sustainable business practices. This is encouraging, as sectors all across the fashion industry from sportswear, footwear, to luxury labels and lingerie, need to develop sustainable products and services which consider environmental, economic, and social issues throughout their product life cycles and value chains [2,5-7].

Designers are repeatedly declared as key agents of change in the transformation to a sustainable fashion industry $[1,3,6,7]$. Being proactive early in the design and manufacturing process is essential for meeting sustainability goals. The designer's role is expanding and should include devising courses of action, no longer avoiding the ethical questions associated with producing and consuming fashion [8]. Designers have the opportunity to increase sustainability in apparel design throughout every phase of the garment life cycle [1,9]. The need for designers to consider all phases throughout the design process in making sustainable fashion is a consistent theme in the literature.

To facilitate the shift towards sustainability, new concepts of design have emerged. Arising out of the ideas of "alternative design", "attitudinal design" and "design for need", eco-design became a key concept for those advocating for the ecologically responsible design of products [10-13]. Eco-design is defined as "a design process that considers the environmental impact associated with a product throughout its entire life from raw materials through production and use to the end of its life" [14] (p. 67). Subsequently, design for sustainability (DfS) was developed and as DfS has evolved, DfS has 
moved from having a technical product-centric focus to recognizing design as a vehicle for large scale systems-level change [15]. In response to the need generated by DfS, a variety of specific tools for sustainable fashion design ("Tools") have emerged to aid designers.

In order to identify existing tools, we have undertaken a thorough search of the literature and websites (institutions, organizations and NGOs). This resulted in the identification of twelve Tools (Table 1) each of which was developed specifically for use by fashion designers with the aim of improving and developing sustainable fashion. There is a wide variety of tools, some are developed by academic exercises while others are developed as industry partnerships, for example the Higg Index was based on Nike's Material Sustainability Index [16]. Other tools exist that include textile materials such as the Idemat and Idemat Light app, a very comprehensive impact assessment tool that also includes eco-cost but does not fall within the criteria of this study [17].

Unfortunately, the methods of the tools are not all described in a way that allows for a parallel organization of the tools, their development and methods. For example, addressing availability of the tools becomes difficult as availability changes over time and is dependent on the groups or individuals searching and accessing the tools. The complexity of dealing with all the variations of the tools is beyond the scope of this paper.

Table 1. Tools for sustainable fashion design.

\begin{tabular}{ll}
\hline Tools & Description \\
\hline $\begin{array}{l}\text { Considerate Design } \\
\text { (CDT) [18] }\end{array}$ & $\begin{array}{l}\text { A simple visual tool for designers to assess the environmental impact of a product } \\
\text { or particular design on eight dimensions: 1. concept design, 2. materials, } 3 . \\
\text { manufacturing, 4. use phase/consumer, 5. customization and personalization, } 6 . \\
\text { durability/longevity, 7. transport, and 8. end of use/disposal }\end{array}$ \\
\hline & $\begin{array}{l}\text { Developed from a designer's point of view especially for small scale production. } \\
\text { The tool is based mainly on of: } 1 \text {. Cradle to Cradle; } 2 \text {. Slow Fashion; and 3. }\end{array}$ \\
Considered Take and & $\begin{array}{l}\text { Functional Design. The model establishes a core category called "considered take } \\
\text { Return (CT\&R) [19] }\end{array}$ \\
& and return" within which all other categories are integrated.
\end{tabular}

The C2CAD model was developed to provide guidelines for apparel designers

Cradle to Cradle Apparel and manufacturers by integrating the Cradle to Cradle model into two existing Design (C2CAD) [20] apparel design and production models [21,22]. The model identifies four main steps where designers and manufacturers should consider environmental impacts in their decision making.

C2C, a not-for-profit organization, created a product standard framework for quality assessment and innovation built upon circular thinking, a biomimetic

Cradle to Cradle Certified Product Standard approach of design and science. C2C Certified created a Fashion Positive Materials Collection, a digital resource of certified materials. The C2C Products (C2C) $[23,24]$ Innovation Institute has also created a sub organization entitled Fashion for Good offering a "How-To" guide for implementing the C2C Certified Product Standard for garment manufacturers.

\begin{abstract}
Higg Index Material Sustainability Index (HIMSI) [16]
\end{abstract}

An assessment scoring tool that measures the environmental sustainability impacts of materials for use in apparel and footwear products. Originally developed by Nike in 2012, the MSI was adopted by Sustainable Apparel Coalition and integrated into the Higg Index. The Higg MSI is publicly available and intended to be used during a product's design phase to understand its predicted impact.

Higg Index Design and Development Tool. Rapid Design Module Beta Version (HI) [16] A product development and design tool that measures the environmental impacts of apparel, footwear and textile products. The RDM provides designers/developers with an internal facing score out of 100 points. The objective of the tool is to engage designers/developers to reduce impact.

A performance tracking tool created by Made-By, a not-for-profit organization, to support fashion brands and retailers improve their sustainability performance.

MADE-BY (MB) [25] sustainability experts. Verification and scoring are conducted by Made-By on a yearly basis. 
Table 1. Cont.

\begin{tabular}{ll}
\hline Tools & Description \\
\hline $\begin{array}{l}\text { Nike Making App } \\
\text { (NMA) [26,27] }\end{array}$ & $\begin{array}{l}\text { A designer specific assessment tool that ranks the environmental impacts of } \\
\text { materials used in apparel and footwear products. The objective is to provide a } \\
\text { reference guide that compares impacts of materials in an accessible easy-to-use } \\
\text { format. Materials are rated out of a score of 50 points. The Nike MSI provides the } \\
\text { data for the model, an app available as a free download from iTunes. }\end{array}$ \\
\hline $\begin{array}{l}\text { Sustainable Design Cards } \\
\text { DSKD (SDC) [28,29] }\end{array}$ & $\begin{array}{l}\text { A set of design cards developed to increase an apparel product's sustainability } \\
\text { through longevity. The tool was created as part of a collaborative case study } \\
\text { between Design School Kolding (DKSD) and Kopenhagen Fur, a local fur } \\
\text { manufacturer. The cards are available as a free download and are intended for } \\
\text { fashion designers. }\end{array}$ \\
\hline $\begin{array}{l}\text { Sustainable Fashion } \\
\text { Bridges Ideation Toolkit }\end{array}$ & $\begin{array}{l}\text { This ideation toolkit is a design thinking tool intended to encourage designers to } \\
\text { consider sustainability from the onset of the design process. The ideation tool } \\
\text { includes a set of } 60 \text { cards using a co-design approach intended to be used by } \\
\text { fashion designers and highly engaged users during the ideation phase of the } \\
\text { design process. }\end{array}$ \\
\hline $\begin{array}{l}\text { Sustainable Fashion } \\
\text { Design Model (SFD) [31] }\end{array}$ & $\begin{array}{l}\text { A model with the aim to support designers in the integration of sustainability } \\
\text { strategies within the design process. The tool requires designers to identify } \\
\text { negative impacts and employ appropriate strategies to reduce or eliminate the } \\
\text { impact. Developed over 5 years using empiric interviews, examination of } \\
\text { garments and practice-led inquiry and is presented from a life cycle perspective. }\end{array}$ \\
\hline TED's TEN [32] & $\begin{array}{l}\text { A practice-based sustainable design tool developed by Textiles Environment } \\
\text { Design, a research centre based out of the University of Arts London. The design } \\
\text { cards are intended to assist designers in creating textiles and apparel that reduce } \\
\text { the environmental impacts of fashion products through a layered design } \\
\text { thinking approach. }\end{array}$ \\
\hline & \\
\hline
\end{tabular}

The aim of this paper is to explore the existing sustainable fashion design tools, and through a comparative analysis, establish their fitness for purpose-that is, the ability of the tools to support and enhance sustainable fashion practice. This notion of fitness for purpose builds on Harvey and Green [33] (p. 17), who state that fitness for purpose "identifies quality in terms of the extent to which a product or service meets the specifications of the customer." To date, no one has undertaken such an analysis of the range of Tools.

Little literature exists regarding the use of sustainable design tools in the fashion industry. Connor-Crabb [34] examined three tools for sustainable fashion design through interviews with the tool developers to determine barriers and opportunities for tool use. The majority of the literature discusses the development of a particular tool, predominately through the description of case studies [19,20,29-31,34-36]. Other studies have identified barriers for designers adopting these tools for sustainable design. A key barrier identified is the limited literature is awareness. Fashion designers are not aware of the existence of these tools nor are they using them [34,37]. Even among designers who are aware of sustainable design tools, inadequate knowledge regarding sustainability and lack of time contribute to an inability to effectively select and adapt tools to their practice $[10,38]$.

Prior studies have also noted that learning mechanisms required to use a tool need to complement the way designers work $[15,34,38,39]$. Information needs to be presented in a style that is suitable for designers [34,39]. Recently, Hur and Cassidy [40] have conducted interviews with fashion designers to identify impediments in implementing sustainability—barriers identified include the lack of design-led approaches for implementing sustainability and perceived trade-offs with other design criteria such as aesthetic styles, costs, and fashion trends. Palomo-Levinski and Hahn's [41] survey of fashion designers identifies that new approaches and a shift to sustainability in education are needed. There is a scarcity of education and understanding of sustainability in fashion, what real innovation for sustainable fashion should become and tangible ways to enact change in creating clothing. They found 
86 percent of respondents agreed "that is was the responsibility of the designer to initiate change" [41] (p. 94).

Learning and use can also become prohibitive as it becomes too time consuming to be carried out on a regular basis [34,39]. This is especially relevant in light of designers citing the lack of consensus and knowledge regarding sustainable fashion and sustainable fashion design as a barrier to its wide scale adoption $[37,38]$. The complexity of sustainability has made it challenging for designers to implement appropriate solutions [34,38,39]—-leading to designers not using or integrating these tools or strategies in their daily design practices [38,39]. This situation highlights an interesting predicament as solutions for sustainability frequently identify designers as key agents of change.

\section{Analytical Framework}

Solutions for sustainability frequently identify innovation, design thinking, systems thinking, and the use of a holistic perspective. Designers are seen as the nexus of technological integration, implementation, decision-making, creativity and novelty. Sustainable design includes understanding of the many complex and interacting issues that must be taken into consideration [15]. Understanding the complexity of sustainable fashion issues can be overwhelming and a barrier for fashion designers, particularly those new to sustainable design [40]. As suggested by Ceschin and Gaziulusoy [15], to obtain a real and lasting impact, there needs to be a greater understanding of the complexity and interacting issues within sustainable design.

This need suggests approaches set forth by designers should aim to incorporate innovation in all aspects of their practice, vision and goals over time, but also to start simply and build complexity over time. Currently, tools for sustainable design fail to fully take the complex idea of sustainability and simplify it into clear digestible resources and actions that provide the foundation for accommodating increasing complexity over time.

Our analytical approach adopted in this paper incorporates three perspectives: innovation levels, dimensions of sustainability, and the interlinking of these as they effect sustainability in the fashion system. The analytical framework was developed based on a review of the literature and the tools reviewed in this paper.

\subsection{Innovation Levels}

Sustainable fashion can be achieved by building incrementally from an initial focus on product-level innovation through to more complex system-orientated levels of innovation. Strategies can be differentiated by the level or degree of innovation. The seminal paper on eco-design by Brezet [42] defines four levels of innovation: 1. product-level improvement, 2. product redesign, 3. function innovation, and 4. system innovation. As Brezet notes, there is increasing innovational freedom in eco-design types as you move from product- to system-level innovation. Similarly, Ceschin and Gaziulusoy [15] identify four levels of innovation within DfS that expand in complexity and innovational freedom from product-level innovation to socio-technical system innovation. In their approaches, innovation stops short of considering the nature of the linkages in the fashion system.

Despite a general recognition in the literature of the need to do so, the frameworks proposed by Brezet [42] and Ceschin and Gaziulusoy [15] do not incorporate elements of the system such as resiliency, adaptability and circularity. In addition, sustainability is not static and must continuously evolve within a set of critical limits [43]. The fashion industry must therefore also be understood as a system with a set of critical limits and a natural sense of disorder. Core considerations such as resiliency and adaptability can ensure the fashion system evolves within the identified set of critical limits. Transitioning to circular economies and closed-loop systems is not a static process nor a utopian ideal but rather a system that should adapt and be resilient. A new level of resilient, adaptable and circular (RAC) innovations, introduced in this paper, incorporates these concepts. 


\subsection{Dimensions of Sustainability}

Traditionally models of sustainability include three dimensions: 1 . environmental, 2 . social, and 3. economic. However, for sustainable fashion design, these can be expanded. Our approach includes a five-dimension model for sustainable fashion by adding 4 . aesthetic, and 5 . cultural dimensions (Figure 1). The dimension of aesthetic sustainability is reflected at the level of the product while cultural sustainability requires a systems-level approach.

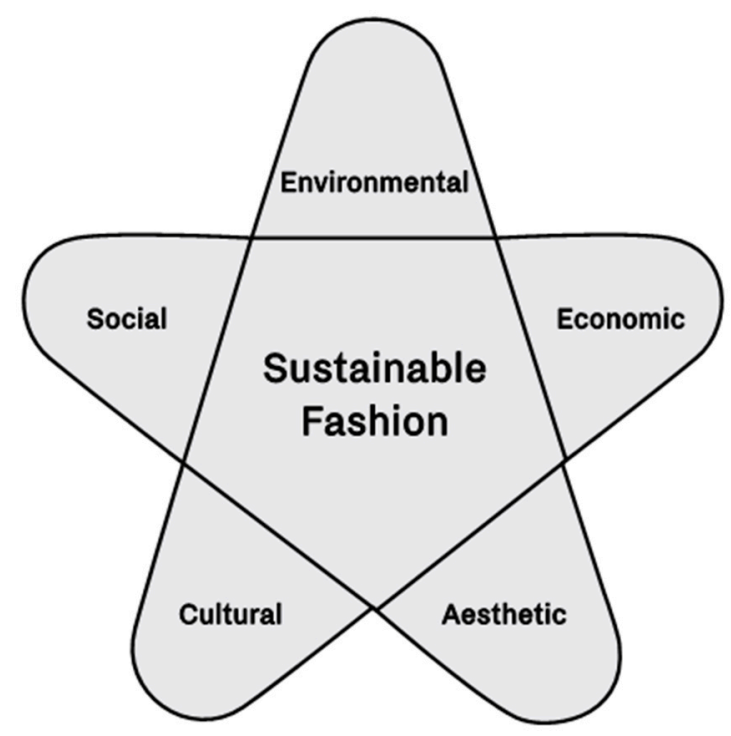

Figure 1. Five dimensions of sustainable fashion.

Harper [44] refers to aesthetic sustainability as timelessness, durability and continuous attraction to an object such as a garment. The work of Chapman $[9,45]$ and the recognition for the need for slow fashion by Fletcher [46] demonstrates that aesthetic sustainability is a central consideration to sustainable fashion. Designing for sustainability in fashion must consider the sustainability of an individual's aesthetic experience $[47,48]$. Our approach in this paper incorporates aesthetic sustainability as an additional dimension.

The cultural dimension of sustainability derives from the notion that concepts of sustainability generally fail to differentiate among cultural systems, value systems, norms, behaviors and ideas and does not recognize the differences in local economies and ecologies. Cultural sustainability involves a shifting of beyond the consideration of social ethics to an acknowledgement of the exploitation of labor and resources and the legacy of colonization. Essingler [49] notes designers should also consider cultural colonialism as industries develop new paradigms of sustainability and sustainable design. This promotes a more holistic perspectives when designers consider the cultural context for sustainable production and consumption. Modern Western culture has a tendency to focus on piecemeal strategies and/or encourages consumption of sustainable products at a higher price point. The Western solution is therefore often focused on recycling rather than reuse and reduction. Recycling does not seek to discourage consumption but maintains the idea that current consumption rates are okay as long as a recycling system is in place. Within Indigenous cultures, sustainability is inherent to their way of life [50]. The fashion industry should consider the inequities throughout the supply chain as the majority of apparel manufacturing occurs in developing countries. These are also the people and communities that can be negatively impacted by the fashion industry. This is an area of sustainable fashion that is yet to be addressed in the academic literature but has entered the sustainable fashion discourse by academics and practitioners within fashion.

The slow fashion movement advocates for increasing the longevity of the usable life of clothing and slowing down of the fashion system by building slow culture through a lens of systems thinking; key to this is recognizing that a sustainable fashion system needs a shift in culture [46,51]. To transform 
fashion, collectively, its cultural sustainability must be considered and addressed [40,52]. There is an industry culture that exists within fashion which is reflected through industry norms and values. Cultural sustainability recognizes the processes and the intrinsic qualities and values embedded in a garment.

\subsection{Interlinkages}

The levels of innovation and the dimensions of sustainability are interlinked and reflect the degree of potential impact of sustainability strategies on fashion. Three levels of impact were recognized as they relate to fashion: 1. "Improvement", 2. "Challenge" and 3. "Transformative". Impact refers to the level of which the tool is designed to affect the fashion system. Improvement occurs at the level of the product and tends to focus primarily on environmental impacts. Challenge addresses change in aspects of the existing system and incorporates four dimensions of sustainability: environmental, social, economic and aesthetic. Transformation changes the fundamental nature and behaviors of a system which requires the holistic inclusion of the five dimensions of sustainability.

This is not to say that strategies for product-level innovation are any less effective than those that are transformative. For example, if all fashion businesses switched to using only organic cotton, collectively this would have a great impact, but not a transformational one. An organic cotton product would still exist in an unsustainable system that does not consider additional processing, use or disposal. Transformative impact would be, for example, the use of organic cotton in a garment produced ethically and embedded in a circular closed-loop system that considers all phases of a garment lifecycle from raw materials to end-of-use, and local ecologies, cultures, social systems and economies [53]. Infrastructure and social behaviors and norms would support the ability for circular closed-loop systems to exist, ensuring garments remain in regenerative loops.

To determine the fitness for purpose of the Tools, four objectives were developed: 1 . to identify existing tools for sustainable fashion design; 2. to create a systematic approach to identify their character and utility; 3 . within each tool, to identify the individual strategies for sustainable fashion design ("Strategies"); and 4. to undertake a critical analysis of the value of the tools as a means for sustainable fashion design. We created a sustainable fashion innovation framework to facilitate the categorization of the Strategies (Figure 2).

\begin{tabular}{|c|c|c|c|c|c|}
\hline \multirow{2}{*}{\multicolumn{2}{|c|}{$\begin{array}{l}\text { Impact } \\
\square \text { Improvement } \\
\square \text { Challenge } \\
\text { Transformative }\end{array}$}} & \multicolumn{4}{|c|}{ Level of Innovation } \\
\hline & & \multirow{2}{*}{ Product } & \multirow{2}{*}{$\begin{array}{c}\text { Product- } \\
\text { service social } \\
\text { system }\end{array}$} & \multirow{2}{*}{ System } & $\begin{array}{l}\text { Resilient, } \\
\text { adaptable } \\
\text { and circular } \\
\text { (RAC) } \\
\text { innovation }\end{array}$ \\
\hline \multirow{5}{*}{$\begin{array}{l}\text { Dimensions } \\
\text { of } \\
\text { Sustainability }\end{array}$} & Environmental & & & & \\
\hline & Social & & & & \\
\hline & Economic & & & & \\
\hline & Aesthetic & & & & \\
\hline & Cultural & & & & \\
\hline
\end{tabular}

Figure 2. Sustainable fashion innovation framework.

\subsubsection{Improvement}

The Improvement category addresses impacts that operate solely at the level of the product. Strategies that are categorized as Improvement are product-level innovations which seek to improve existing and/or develop novel products [15]. Most seek incremental improvements that are low hanging fruit. While they may also target social dimensions of sustainability, product-level innovations are largely environmentally-driven, insular, and short-term [15,42]. They do not incorporate economic or financial considerations such as new sustainable business models. Approaches, strategies and 
innovations at the level of the product generally involve one or more of: 1. product improvement, 2. production process improvement, and 3. product redesign. Examples of Strategies categorized within this level include those in which the environmental consideration is the basis for opting for renewable energy sources, designing for reuse, implementing zero waste pattern drafting, and sourcing environmentally friendly or low impact materials.

\subsubsection{Challenge}

Strategies classified as Challenge are those which focus on impacts that target individual behavioural change. This requires a more holistic perspective and the use of systems thinking. Applying systems thinking within the fashion context entails a broader view of sustainability, one that incorporates four dimensions: environmental, social, economic and aesthetic. Design approaches need to live in new conceptual spaces that consider many more aspects such as the temporality, processes, inputs and outputs of production and consumption of products and services within broader social contexts; essentially shifting to a holistic viewpoint of the fashion system. Systems thinking pushes designers to consider both how the industry is organized, and the resulting behaviors (individual and systems level). Understanding current behaviors opens up exploration into how behavior change principles can encourage people to act in ways that benefit the planet. Those Strategies which address impacts that Challenge the fashion industry have influence at two levels of innovation: 1. product-service social systems, and 2. systems innovation.

Innovations at the level of product-service social system begin to challenge current system norms and operations within the fashion industry. These include changes to the traditional business model in fashion [54]. Product-service systems move away from the traditional linear model that produces individual products towards integrated combinations of products and services. This typically involves the development of new business models with value propositions oriented to satisfy users through the delivery of services instead of products [15]. Integrating sustainability strategies into the role of designers requires that they engage with the models of business [55] and adopt new sustainable models into existing, and for new, fashion businesses [37].

Drawing on Manzini's [56] ideas of Design for Social Innovation and Ceschin and Gaziulusoy's [15] spatio-social system innovation type, we propose the product-service social systems innovation for sustainable fashion: a sustainable design approach that integrates products and services that considers societal needs and social innovation at different scales, for example decisions from that of the individual designer to the fashion industry itself. Collaborative work and community building are central to orientating, implementing and sustaining processes of social change through design. This includes consideration of four dimensions of sustainability: environmental, social, economic and aesthetic. Examples of these Strategies categorized within this level include adopting co-design, services for longer or intense utilization, rental services, designing modularity into garments, open-source fashion platforms, and community learning opportunities.

Systems innovations are those which begin to tie together product-level innovation and sustainable business models to the larger existing operations and infrastructure of the industry. Brezet [42] identifies two types of innovation that exist within a systems-orientated lens: 1 . the conceptual definition of new products, and 2. the definition of new production systems. These types of innovation necessitate changes to infrastructure and organizations that are required to support products and services [42]. Innovations draw upon systemic design approaches, in which local production systems are designed with waste from one production process becoming input for other processes [15]. Examples of Strategies categorized within this level include design activism, design for social innovation, rethinking durability or creating open-source networks.

\subsubsection{Transformative}

Transformative Strategies seek to "transform the way clothes are designed, sold, and used to break free from their increasingly disposable nature" [57] (p. 24) in order to achieve a sustainable fashion 
system. Transformation of this magnitude dictates culture change where social behaviors are the focus. Strategies categorized at this level focus on innovations that emphasize reducing consumption and increasing circularity, adaptability and resiliency within unstable systems. Additionally, the RAC innovation level considers all five dimensions: economic, environmental, social, aesthetic and cultural.

The cultural dimension is an area severely under-addressed within sustainable fashion. Incorporating the cultural dimension ensures we do not propose the same blanket solutions globally and consider local systems. Supporting a sustainable fashion system in France could look dramatically different than what would work in Brazil, Bangladesh or Australia. This includes considerations such as local culture, political climate, economy and infrastructure. A cultural dimension also includes issues around postcolonialism and diversity. Sustainability issues such as climate change and biodiversity loss disproportionately harm the poorest people - the very people who often manufacture fashion clothing [58]. To ensure all stakeholders and voices along the fashion value chain are part of the solution, collaboration and transparency are vital for transformative change that includes new cultural narratives around sustainability.

The fashion industry has become incredibly complex, [40,57] unpredictable and subject to disruption. There is a need therefore to recognize that there is a natural sense of disorder in existing systems, rather than an idealized system that rests in a harmonious balance [43]. Thus, in the transition to circular economies and closed-loop systems, resiliency and adaptability must be a core consideration.

Circularity is key component of transformative change. Redesigning of a linear system towards a circular economy with material regeneration at its core that includes local and global scales and alignment with the various speed cycles that exist in fashion (fast vs. slow fashion). Earley [59] discusses sustainable design strategies and the importance of considering speeds within the context of circular fashion. Circularity requires both that lifecycle phases of a garment be considered at the design stage and that the original design needs to consider the phases within different speed cycles [59]. Circular economies are based on principles of closed loops and are restorative and regenerative by nature. Natural systems are regenerated, and economic growth is decoupled from consumption of finite resources [60]. Design for circular economies considers certain core principles which must be embedded into the design process. Principles such as ensuring "clothes, fabric, and fibres are kept at their highest value during use, and re-enter the economy after use, never ending up as waste" [57] (p. 22).

Design is therefore used to understand and solve complex problems, building upon the various levels of innovation and Strategies. Perspectives are broad and holistic and focus on developing new cultural norms and narratives that support sustainability with a positive impact on the future well-being of earth and its living systems. The goal is radical change that support ecological, economic, social, cultural and aesthetic needs by exploring synergies of multiple approaches, methods and strategies through a lens of systems thinking. Exploring synergies of multiple approaches requires foresight, meaning research and development time is crucial to creating these circular systems, as is openness to new technologies such as artificial intelligence. Artificial Intelligence is crucial to circular economies as it has the capabilities to support faster and more agile learning processes with iterative cycles of designing, prototyping and gathering feedback. This is necessary in a transition to an economy focused on keeping products and materials in use [60]. Designers must embrace their new role which requires a more multi-faceted, collaborative and transparent approach. Examples of Strategies include designing for different speed systems, working within geographic fibresheds (i.e., working with plants, animals, materials and fibres found within the local geography), developing localization and addressing power shifts.

\section{Analysis}

The framework for the analysis was derived from a close examination of the tools. It was clear that the tools incorporated a wide variety of different sustainability strategies. The strategies were initially coded and categorized by the phases of a garment lifecycle which the tools incorporate. The strategies 
were also coded based on the five dimensions of sustainability. Based on this initial coding process, it became evident the potential impacts of the strategies differed (i.e., improvement, challenge and transformative).

The analysis of the tools was conducted through the development of: 1. a heatmap, 2. a parallel coordinate plot, and 3. a cluster analysis. Each of these provides a means for the visualization of the nature and relationships among the tools. Initially, the attributes and strategies were identified:

1. The basic nature (the "attributes") of the tool (i.e., approach, scope, basic structure, purpose, application and character) as described in the instructions, descriptions, reviews and case studies;

2. The strategies (i.e., design types, methods, initiatives, strategies, approaches, and examples).

Categorization of the attributes and strategies was done inductively [61].

\subsection{Heatmap Development}

Heatmaps have been widely used in the literature to represent row and column hierarchical cluster structures of data in a rectangular colour-shaded matrix display. The matrix is a series of tiles represented by a shade from a colour scale to denote a value of the corresponding element of the data. The heatmap is typically used in the natural sciences to display large, complex data sets with hierarchical cluster trees appended to its margins [62]. For the purposes of this paper, we have used a simplified version of a heatmap as our dataset is considerably smaller than the typical datasets used within the natural sciences for bioinformatics display.

Among the twelve Tools, 520 Strategies were identified (Table 2). Among these, 367 distinct Strategies were identified of which $324(88 \%)$ were classified as product-level innovation, $21(6 \%)$ were product-service social innovation (PSSS), 17 (5\%) were system innovation and $5(1 \%)$ involve resilient, adaptable and circular (RAC) innovation. At the product-level, $70 \%$ of strategies at this level are unique to a specific tool and not used by any other tool. Among Strategies categorized at product-level innovations, $80 \%$ are solely focused on impacts of an environmental nature.

Table 2. Categorization of strategies for sustainable fashion design (SSFD) by impact and innovation level.

\begin{tabular}{cccccc}
\hline & \multicolumn{5}{c}{ Impact and Innovation Level } \\
\cline { 2 - 5 } & Improvement & \multicolumn{2}{c}{ Challenge } & Transformative & \multirow{2}{*}{ Total } \\
\cline { 2 - 5 } & Product & PSSS & System & RAC & \\
\hline Count of unique SSFD & 324 & 21 & 17 & 5 & 367 \\
Total count of SSFD & 466 & 28 & 18 & 8 & 520 \\
Count of environmentally focused SSFD & 375 & 14 & 8 & 0 & 397 \\
\hline
\end{tabular}

PSSS: product-service social innovation; RAC: resilient, adaptable and circular innovation.

A heatmap (Figure 3) was created which highlights the distribution of the Strategies categorized by innovation levels and system impact. The heatmap indicates the number of Strategies classified at the levels of innovation and impact on fashion for each Tools. Each tool includes a focus on product-level innovation; five are solely designed to do so. Only three tools, CT\&R, SFB and Ted's Ten, incorporate Transformative consideration. The others consider some elements of PSSS, System or RAC, but these Strategies are few in number. The heatmap highlights the interlinking of the innovation levels, potential impact and strategies used. The relationship among strategies, innovation levels and potential impact becomes visible, demonstrating a difference among the various tools. 


\begin{tabular}{|c|c|c|c|c|c|}
\hline & \multicolumn{4}{|c|}{ Level of Innovation } & \\
\hline & PRODUCT & PSS & SYSTEM & RAC & \\
\hline \multicolumn{5}{|l|}{$\begin{array}{l}\text { NIKE MAKER } \\
\text { APP }\end{array}$} & \\
\hline \multicolumn{5}{|l|}{$\begin{array}{l}\text { HIGG INDEX } \\
\text { MSI }\end{array}$} & \\
\hline \multicolumn{5}{|l|}{ HIGG INDEX } & \multirow{2}{*}{$\begin{array}{l}\text { Number of } \\
\text { Strategies }\end{array}$} \\
\hline \multicolumn{5}{|l|}{$\mathrm{C} 2 \mathrm{C}$} & \\
\hline MADE-BY & & & & & \multirow{5}{*}{$\begin{array}{l}>40 \\
11-40 \\
5-10 \\
<5\end{array}$} \\
\hline C2CAD & & & & & \\
\hline FDS & & & & & \\
\hline \multicolumn{5}{|l|}{ SDC } & \\
\hline \multicolumn{5}{|l|}{ CDT } & \\
\hline \multicolumn{5}{|l|}{ CT\&R } & \\
\hline \multicolumn{5}{|l|}{ TED'S TEN } & \\
\hline \multicolumn{5}{|l|}{ SFB } & \\
\hline & IMPROVE & \multicolumn{2}{|c|}{ CHALLENGE } & TRANSFORM & \\
\hline & \multicolumn{4}{|c|}{ Impact on Fashion } & \\
\hline \multicolumn{2}{|l|}{ Nike Maker App } & \multicolumn{3}{|c|}{ FDS: Fashion Design Sustainability } & \\
\hline \multicolumn{2}{|l|}{ Higg Index MSI } & \multicolumn{3}{|c|}{ SDC: Sustainable Design Cards } & \\
\hline \multicolumn{2}{|l|}{ Higg Index } & \multicolumn{3}{|c|}{ CDT: Considered Design Tool } & \\
\hline \multicolumn{2}{|c|}{ C2C: Cradle to Cradle } & \multicolumn{3}{|c|}{ CT\&R: Considered Take \& Return } & \\
\hline \multicolumn{2}{|l|}{ Made-By } & \multicolumn{3}{|c|}{ TED'S TEN: Ted's Ten Environmental Design } & \\
\hline \multicolumn{2}{|c|}{ C2CAD: Cradle to Cad Design } & \multicolumn{3}{|c|}{ SFB: Sustainable Fashion Bridges } & \\
\hline
\end{tabular}

Figure 3. Heatmap of strategies for sustainable fashion design.

\subsection{Parallel Coordinate Plot}

To better appreciate the overall nature of the tools, a parallel coordinate plot (PCP), a useful tool for visually examining multivariate data, was developed. This allows for comparison of multiple design tools among many design dimensions and variables [63,64]. Pousman and Stasko [63] and Wölfel and Merritt [64] have used PCPs to better understand design frameworks by comparing their attributes along various design dimensions. A major advantage of PCP is the capacity for comparison of multiple variables within an identified design dimension (e.g., the scope and the purpose of tool). The aim of applying this method is to determine whether any patterns exist.

To appreciate the benefits of current sustainable design tools, we conducted a survey of their attributes. Initially, four out of the five design dimensions from the Wölfel and Merritt [64] study were deemed to be appropriate: 1. Purpose and Scope, 2. Duration, 3. System, and 4. Formal Qualities. For this study, five additional attributes were identified: 5. Categorization, 6. Accessibility, 7. Format, 8. Scoring/Assessment, and 9. Sustainability Dimensions. These nine design dimensions form an axis, which allows for a visual comparison when tool attributes are plotted along the dimensions, creating the PCP. The axes reflect the unique characteristics of sustainable fashion design identified throughout 
the coding process. Plotting of the attributes of the twelve Tools across the nine design dimensions allow for any patterns to become apparent. Patterns highlight similarities and differences among the Tools. The Tools are grouped based on similarities and differences to distinguish and identify any archetypes. Graduations within the design dimensions are used to differentiate the Tools [64]. Descriptions of the nine design dimensions and the graduations within each are listed in Table 3.

Table 3. Descriptions of the nine design dimensions of the parallel coordinate plot (PCP).

\begin{tabular}{|c|c|}
\hline $\begin{array}{c}\text { Design } \\
\text { Dimensions }\end{array}$ & Description \\
\hline Categorization & $\begin{array}{l}\text { Three types of frameworks are used to organize information contained within the Tools. } \\
\text { All of the tools identified and positioned themselves within certain types of frameworks, } \\
\text { guiding the underlying philosophies of the tools: } 1 \text {. design types, } 2 \text {. apparel design model } \\
\text { thinking/design thinking, and 3. life cycle phases of garments. }\end{array}$ \\
\hline $\begin{array}{l}\text { Purpose and } \\
\text { scope }\end{array}$ & $\begin{array}{l}\text { Look at the goal or aim of the tool and whether the Tools focus on a particular context. } \\
\text { Three graduations were used as identified by Wölfel and Merritt [64]: 1. general, } \\
\text { 2. participatory design, and 3. context specific/agenda-driven. }\end{array}$ \\
\hline Duration & $\begin{array}{l}\text { Duration looks at the length of use of the Tools throughout the design process and whether } \\
\text { they are to be used at specific points within the process. This dimension addresses key } \\
\text { differences in length of time and point of time the Tool is to be used: } 1 \text {. anywhere/anytime, } \\
\text { 2. as needed/beginning of, and 3. specific point. }\end{array}$ \\
\hline System & $\begin{array}{l}\text { Refers to methodology of use, as some Tools are used quite freely with no suggested } \\
\text { structure while others provide specific instructions on use [64]. Tools are created with an } \\
\text { intended approach and use by designers or a system of use. Three types were found } \\
\text { among the tools: } 1 \text {. no system, } 2 \text {. suggestions for use, and 3. specific instruction. }\end{array}$ \\
\hline Accessibility & $\begin{array}{l}\text { Accessibility is a major factor in a designer's ability to use existing tools. Three main } \\
\text { categories were found within this dimension: } 1 \text {. buy tool/journal article, } 2 \text {. free digital } \\
\text { download/access, and 3. paid membership required. }\end{array}$ \\
\hline Format & $\begin{array}{l}\text { Tools are classified by their format for use. How a designer interacts with tools is tied to } \\
\text { their format such as physical cards, inputs through an online platform or a } \\
\text { two-dimensional model drawing. Four formats were found among the tools: } 1 \text {. cards, } \\
\text { 2. models, } 3 \text {. standards and } 4 \text {. impact assessment. }\end{array}$ \\
\hline Formal qualities & $\begin{array}{l}\text { Formal qualities look at how the tool is organized for use. Three categories represent the } \\
\text { range of design tools: } 1 \text {. categories, } 2 \text {. only text/models, and } 3 \text {. online } \\
\text { platforms/components. }\end{array}$ \\
\hline $\begin{array}{c}\text { Scoring/ } \\
\text { assessment }\end{array}$ & $\begin{array}{l}\text { Scoring/assessment determines the type and level of assessment employed by design tools. } \\
\text { The tools were found to have either: } 1 \text {. no assessment, } 2 \text {. levels, and 3. metrics } \\
\text { (quantifiable scores). }\end{array}$ \\
\hline $\begin{array}{l}\text { Sustainability } \\
\text { dimensions }\end{array}$ & $\begin{array}{l}\text { This represents the various dimensions of sustainability addressed by the tools. Three } \\
\text { variations of sustainability dimensions were found among the tools: } 1 \text {. Environmental, } \\
\text { social and aesthetic, } 2 \text {. Environmental and social and } 3 \text {. Environmental. Economic } \\
\text { sustainability was not prevalent and frequently addressed as a secondary consideration } \\
\text { under environmental or social sustainability. }\end{array}$ \\
\hline
\end{tabular}

We identified archetypes by grouping those tools that are generally similar as Universal, Participatory, and Assessment (Figure 4). Three of the Tools are classified as Universal, two as Participatory and seven as Assessment. The tools classified in each of the archetypes share a common set of characteristics. Table 4 provides a summary of these. 


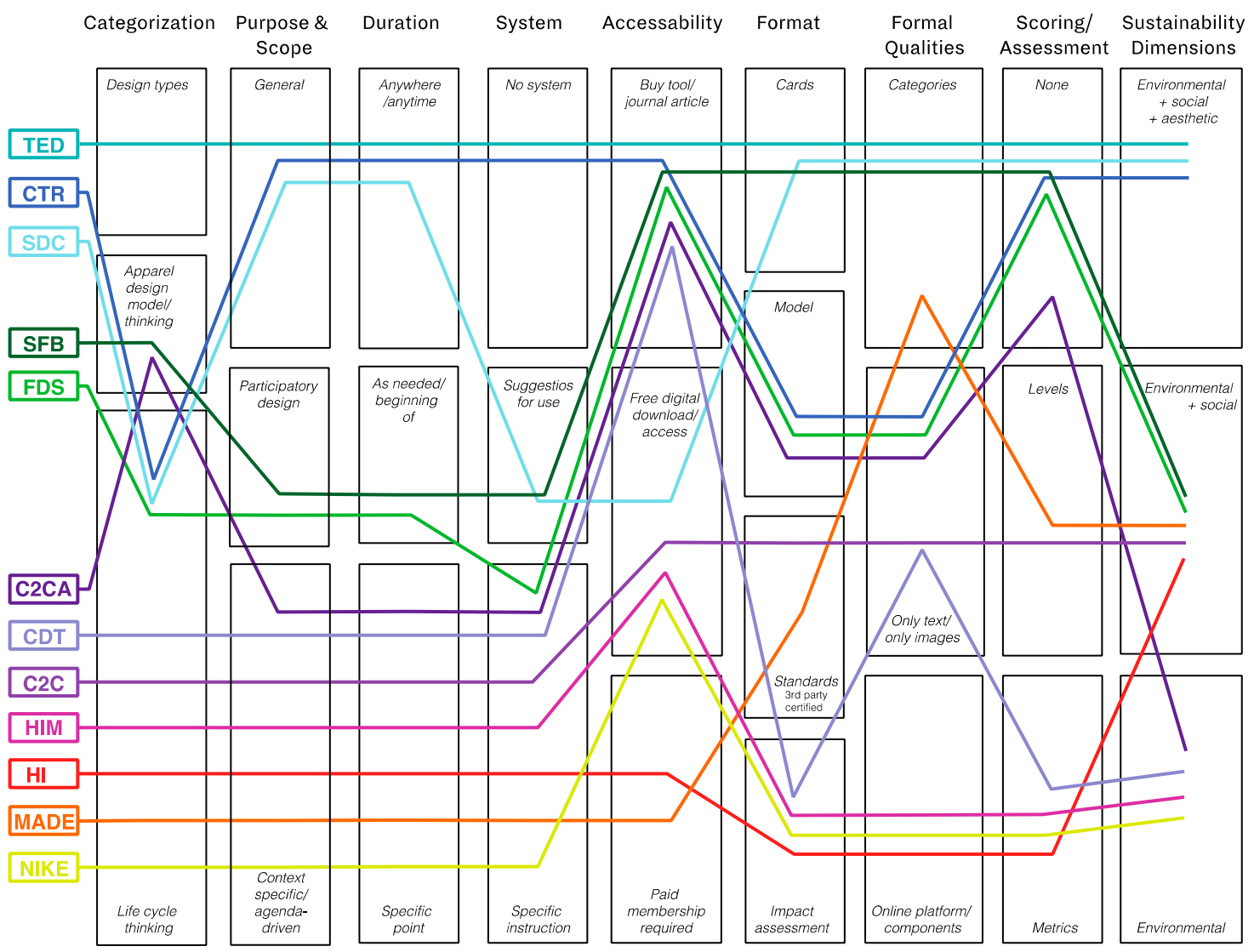

Figure 4. Parallel coordinate plot of the Tools.

Table 4. Tool Archetype descriptions.

\begin{tabular}{|c|c|c|c|}
\hline & Description & Distinguishing Characteristics & $\begin{array}{c}\text { Sustainability } \\
\text { Dimensions }\end{array}$ \\
\hline $\begin{array}{l}\text { Universal } \\
\text { - } \quad \text { Ted's Ten } \\
\text { - } \quad \text { Considered Take } \\
\quad \text { E Return } \\
\text { - } \quad \text { Sustainable } \\
\quad \text { Design Cards }\end{array}$ & $\begin{array}{l}\text { Tools are an inspirational } \\
\text { compendium of } \\
\text { sustainable design } \\
\text { strategies for designers } \\
\text { to integrate as they see fit } \\
\text { into their design practice }\end{array}$ & $\begin{array}{l}\text { - } \quad \text { Do not have a specific duration or } \\
\text { system for use. } \\
\text { Can be easily applied and used within } \\
\text { any part of the design process } \\
\text { depending on Strategies selected } \\
\text { - Minimal to no instruction on their use } \\
\text { as they are intended to be general } \\
\text { Guidance comes in the form of } \\
\text { examples and further readings, } \\
\text { leaving further learning for the } \\
\text { designer to seek out. } \\
\text { Information is presented in an easy to } \\
\text { use format such as visual } \\
\text { two-dimensional models and/or } \\
\text { physical cards }\end{array}$ & $\begin{array}{l}\text { Environmental, } \\
\text { social and } \\
\text { aesthetic }\end{array}$ \\
\hline
\end{tabular}


Table 4. Cont.

\begin{tabular}{|c|c|c|c|}
\hline & Description & Distinguishing Characteristics & $\begin{array}{c}\text { Sustainability } \\
\text { Dimensions }\end{array}$ \\
\hline $\begin{array}{l}\text { Participatory } \\
\text { - } \quad \text { Sustainable Fashion } \\
\text { Bridges } \\
\text { Ideation Toolkit } \\
\text { - Sustainable Fashion } \\
\quad \text { Design Model }\end{array}$ & $\begin{array}{l}\text { Tools prescribe various } \\
\text { approaches for co-design } \\
\text { methods where } \\
\text { designers build empathy } \\
\text { and engage consumers in } \\
\text { the design process. This } \\
\text { builds sustainability } \\
\text { through added- value by } \\
\text { enhancing consumer } \\
\text { experience and } \\
\text { emotional durability of } \\
\text { both product and } \\
\text { process. }\end{array}$ & $\begin{array}{l}\text { - The designer is central to this process, } \\
\text { seeking change on a deeper level that } \\
\text { is long term. } \\
\text { Intended to be used at the beginning } \\
\text { and then as needed throughout the } \\
\text { design process, depending on how } \\
\text { involved the consumer is in the } \\
\text { co-design process. } \\
\text { - Instructions and context of use are } \\
\text { more specific than Universal } \\
\text { Design process is extended/more } \\
\text { time consuming } \\
\text { Information is presented in an easy to } \\
\text { use format such as visual } \\
\text { two-dimensional models and/or } \\
\text { physical cards }\end{array}$ & $\begin{array}{l}\text { Environmental } \\
\text { and social }\end{array}$ \\
\hline $\begin{array}{ll}\text { Assessment } \\
\text { - } & \text { C2C } \\
\text { - } & \text { C2CAD } \\
\text { - } & \text { Considered } \\
& \text { Design Tool } \\
\text { - } & \text { Higg Index } \\
\text { - } & \text { Higg Index MSI } \\
\text { - } & \text { Made-By } \\
\text { - } & \text { Nike Maker App }\end{array}$ & $\begin{array}{l}\text { To identify and reduce } \\
\text { negative environmental } \\
\text { and social impacts of } \\
\text { products and production } \\
\text { processes. }\end{array}$ & $\begin{array}{l}\text { - } \quad \text { Agenda driven and } \\
\text { are context-specific } \\
\text { - } \quad \begin{array}{l}\text { Are used at specific points within the } \\
\text { design process }\end{array} \\
\text { - } \quad \text { Categorized by life cycle phases } \\
\text { - } \quad \text { Require specific instruction on use } \\
\text { - Utilize a scoring mechanism to } \\
\text { assess impacts } \\
\text { - Require working with suppliers and } \\
\text { factories to collect, monitor and } \\
\text { improve upon environmental impacts } \\
\text { Provide excellent additional support } \\
\text { to tools categorized under } \\
\text { Participatory and Universal }\end{array}$ & $\begin{array}{l}\text { Largely } \\
\text { Environmental } \\
\text { with minimal } \\
\text { attention to the } \\
\text { social } \\
\text { dimension }\end{array}$ \\
\hline
\end{tabular}

\subsection{Tools Classification}

To provide a holistic visual representation of the Tools we combined all the information into a single figure. We used a cluster analysis approach: a "cluster analysis" being a generic name for a wide variety of procedures that can be used to create a classification [65]. In this study, we used a heatmap and PCP to begin identifying groupings or clusters. By combining the results of the two approaches, we created a graphical representation for the categorization of the Tools, as shown in Figure 5.

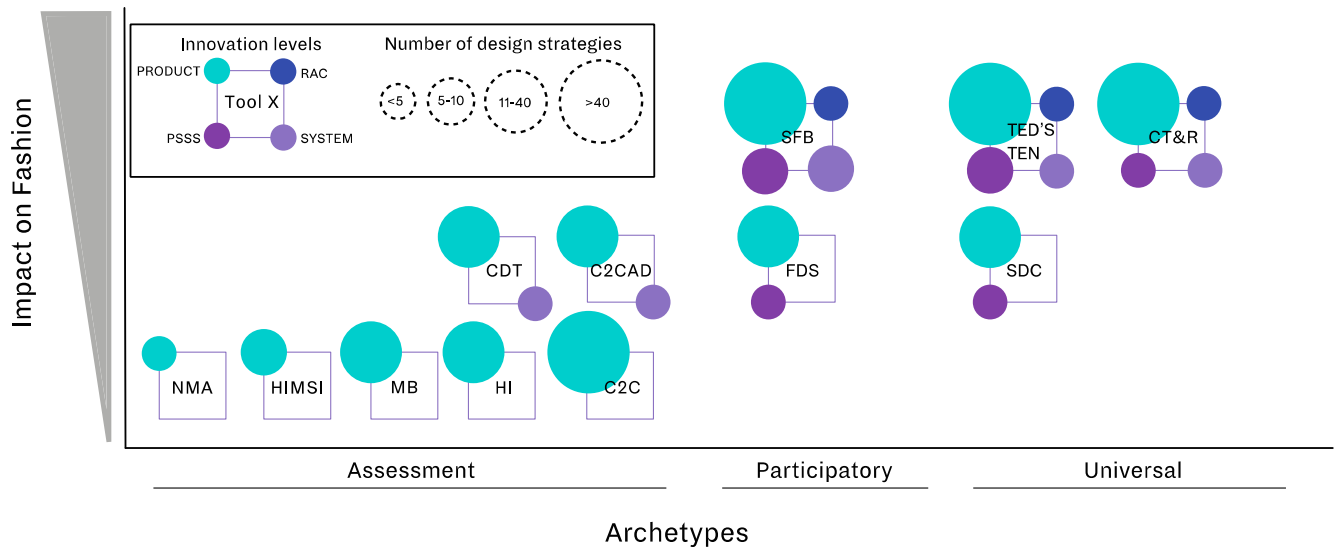

Figure 5. Classification of Tools. 
Figure 5 was constructed to group the three different archetypes. The vertical axis represents an increasing system impact of the archetypes based on levels of innovation-this reflects the impact on fashion. The circle size indicates the number of strategies within each archetype. For example, Ted's Ten includes 82 strategies at product-level innovation, 8 strategies at the PSSS level innovation, 3 strategies at the system-level innovation and 3 at the RAC level innovation. Classifying the Tools by level of innovation and count offers an impression of the potential system impact a designer could expect by using a particular Tool archetype. As a composite of the previous figures and analysis, Fig. 4 demonstrates that those tools categorized as Assessment are primarily focused on product level innovations. Tools such as the Higg Index prioritize strategies the reduce environmental impact of product and processes using LCA's and metric indicators to assess, monitor and improve identified impacts (e.g., reducing water usage or eliminating hazardous chemicals). Those tools that are more conceptual and seek to change how designer's work (e.g., behaviours and culture) and includes strategies that contextualize sustainability beyond the product. For example, Ted's Ten promotes design activism, a strategy that moves beyond products to consider designing events and communication strategies, targeting behaviours, lifestyle and culture change [32]. The designer assumes a role of a social innovator to activate positive societal changes for a sustainable fashion system.

\section{Discussion}

This study offers the first comparative analysis of the Tools and an evaluation of their fitness for purpose for fashion design. Only one study has examined three tools through interviews with developers to determine barriers and opportunities for use [34]. The majority of studies into design tools typically document the development of a tool through a case study (e.g., [27,28]). Essentially, the literature demonstrates much work is still needed as many barriers still exist for tool adoption and the integration of sustainability into design practices by designers for a variety of reasons.

To better understand the landscape of Tools within fashion, this study resulted in the creation of a Sustainable Fashion Innovation Framework and the identification of three tool archetypes: Assessment, Participatory and Universal. The Assessment tools differ significantly in the number of strategies they incorporate. However, they all primarily focus on the environmental dimension of sustainability-with social dimensions also considered in a minority of the tools. The purpose of these Tools is to aid designers throughout the design and product development process. They highlight the potential impacts a designer would encounter. These tools have been primarily developed through industry partnerships. The Participatory tools are characterized very specifically by engaging the consumer in the design process. These are specialized approaches that use co-design as their framework. The premise is that sustainability is enhanced when consumers are involved in the design and product development process as their perceptions and values towards garments are altered. These tools provide strategies to facilitate the concept. The Universal tools are inspirational in their character. They are a compendium of the various sustainable design methods, approaches, strategies, information sources and examples. They offer the greatest breadth of opportunity for integrating sustainability into the design process; however, they have limited to no instruction for use. These tools give the greatest freedom for designers to make choices about their design practice which may make them appealing.

Many of the Strategies identified overlap and are complementary. Solutions to sustainability do not exist in a vacuum, they must be holistic and be able to build upon each other as they increase in complexity. Tools should look to guide designers in how to frame the problem and consider alternative lenses when designing. These findings may help designers find new ways of combining Strategies and Tools that complement one another. Most designers begin working on sustainability in one area, like sourcing more sustainable materials, eliminating bad chemicals from products, or focusing on fair trade labor practices. While those efforts make a difference, sustainability does not start and stop with one initiative alone. Tools should be viewed within a landscape of tools where tools tackle different facets of the issues the fashion industry is facing; for example, Assessment tools pair well with those 
from the Universal or Participatory archetypes. Universal tools that suggest co-design methods could direct designers to Tools categorized as Participatory.

Key findings from this analysis include tool access and awareness, barriers for uptake, positive attributes and recommendations for tool development. Many barriers for tool uptake by practitioners were identified. One of the critical issues is tool accessibility. Tool access is problematic for several reasons. The majority of sustainable fashion designers are MSEs [37]; there is a financial barrier (especially for Assessment Tools) as membership, or consultation fees are quite expensive as they (e.g., Higg Index, Made-By, Cradle-to-Cradle, C2CAD) have been developed by and for large corporate businesses. In addition, these tools typically require extensive expertise, time commitments and third-party auditing. As these Assessment Tools are intended for designer use, they are quite technical and require training or learning for use. In reality, they do not speak to designers, can be confusing and difficult to use as they have been found to be unappealing to fashion designers, cited as being too technical and scientific [37].

Distinct from those designed for large corporations, each of the Universal and Participatory Tools was the result of a project-based academic initiative. These tools were developed for designers working in small companies. To provide access for fashion designers they have minimal to no cost. These tools experience barriers due to a lack of the funding that allows the tools to be updated and readily available; in addition, funding may not be available for tool testing, customizing, updating and promoting as these are dependent on time and resources within the scope of a project [34]. Certain tools are no longer available online or for purchase.

Tools that are available for free are difficult to find as they exist in different platforms and spaces such as websites, journals, academic books, apps or physical cards. This begs the question how designers with limited resources, time and access would successfully locate these tools. If designers are able to locate these tools, implementing tools independently at the very least requires an investment of time on behalf of the user [34,39], a difficult endeavor for MSE fashion designers.

There is also no guidance for designers as to what tool is most appropriate for them. These tools tackle different facets of the sustainability issues within fashion and therefore have specific focuses and concomitant limitations. As suggested by Connor-Crabb [34], successful implementation in practice is contingent on how clearly the application and limitations of a tool is described. What we found is certain tools are suited to be used together and inter-changeably. Tools currently exist in vacuums with little guidance on how to use them as a suite that work with each other. As stated previously, these tools contain many different Strategies which could leave designer's perplexed as to which Strategies are best suited for their goals and business, which ones they should implement, how to implement and in which order. Organizing Strategies by innovation level and impact could potentially assist designers in choosing which product level innovation strategies best suit the long-term goals and vision of a designer or business. The last barrier is tool appeal. Tools must be appealing to designers to use. This includes aspects such as format (app, cards, model, text), aesthetics (use of graphics and symbols over text) and ease of use. The literature cites the most popular and appealing tools to use were those in a card format [64]).

Learning is required to use the tools and implement Strategies recommended by the tools. Research and reading are necessary for developing fundamental knowledge and tool usage is dependent on a designer's level of knowledge. Learning and using tools is time-consuming. This includes planning, implementation, action, monitoring and sustaining a sustainability plan. For designers, this adds time and cost to activities such as sourcing materials, vetting factories and auditing/monitoring factories and their supply chain. The financial commitment and resources are quite high as they require costly initial investments upfront before any product is even sold. This can be a high-risk endeavor for MSE businesses. The complexity of sustainable fashion itself can be an overwhelming task for designers, especially sustainable fashion design entrepreneurs. Given this complexity, we find the guidance or "how-to" component of the tools to be minimal. All of the tools contain many Strategies and a variety of forms of ancillary information. This typically entails providing descriptions, definitions, examples 
and further readings but lacks the "how-to" component to integrate these strategies into a fashion business and design practice.

Tools that were seen as easiest to use as an independent or MSE designer were those that provided examples, case studies and provided further reading. These tools are in a card format and available as free downloads. The format of the Assessment tools is suitable for experts in sustainable production and supply chain management rather than designers. The Universal and Participatory tools are better suited for MSE designers while it was found the Assessment tools are more suitable for large corporations. Large corporations were involved in the development of some of the tools (e.g., Higg Index, C2C). Only large corporations have the capabilities and resources to implement dedicated teams for their use.

\section{Conclusions}

Given the variety of tools available, several recommendations are offered for tool developers based on the fitness for purpose of the tools. First, there are advantages for tools to be developed to work with other tools. Lofthouse [39] highlights the significance of tool suites as "nothing does everything" and no tool "offers a one-size-fits-all solution" [10] (p. 557). Second, tools should be targeted to how designers work; they must speak their language. Tools that tended to be more visually based and intuitive were those that were developed in conjunction with designers (e.g., Sustainable Design Cards, Ted's Ten). Third, context is extremely important, and tools should identify the best context for their use or be developed for specific contexts (e.g., workshops, daily use, strategic planning). Designers need to consider and embed transformational Strategies if the industry is to enact the change needed for a sustainable fashion system. Fourth, Strategies categorized at the Transformative level are minimal in number and developers should consider including higher level Strategies to assist designers with the transition to a sustainable fashion industry. The final recommendation would be to rethink the role of the designer beyond a creator of garments; MSE designers often fulfill multiple roles [37] and tools should acknowledge these. This can include tool support, training workshops or opportunities to work with academic researchers in tool development.

This study contributes the first comparative analysis of the fitness for purpose of the existing tools for sustainable fashion design, resulting in the identification of three tool archetypes: 1. Universal, 2. Participatory, and 3. Assessment. To analyze the tools, we developed an innovation framework to categorize the Strategies contained within the Tools. Four levels of innovation have been proposed: 1. product-level, 2. product service social systems level, 3. systems level and 4. resilient, adaptable and circular level. We found that the majority of the Strategies presented by the Tools were limited to product-level innovations. The impact of Strategies categorized at the product-level is limited to improvements rather than transformational change. Assessment tools predominately prescribed to Strategies that are categorized as product-level innovation and addressing the environmental dimension of sustainability. The interrelation between the archetypes, the innovation framework and strategies reinforce the notion that sustainability can be approached at multiple levels. For designers, sustainability must be approached in manageable pieces (product-level innovation and associated strategies) but are related and moving towards the bigger systems thinking vision that a designer has established (through to RAC innovation and associated strategies). By establishing a vision and long-term goal that seeks transformational impact, a designer can select appropriate and manageable strategies, directly related to their long-term goal, that improve and challenge the current system. Designers are therefore working within this duality of a very specific focus embedded within a systems thinking big picture lens-moving within the two.

The Universal and Participatory tools contained Strategies found within all innovation levels and are most suitable for MSE designers. Therefore, in terms of fitness of purpose, the Universal and Participatory tools are deemed to be most appropriate for designers based on the results. The Universal and Participatory tools are also well-suited for use in conjunction with Assessment tools. Through the analysis, we have identified barriers, opportunities and further recommendations for tool developers. 
We have also proposed a new sustainability framework specific for fashion that includes five dimensions: 1. Environmental, 2. Economic, 3. Social, 4. Aesthetic and 5. Cultural. We find that to build a sustainable fashion industry, designers should consider and incorporate the proposed five dimensions of sustainability for fashion and the four levels of innovation throughout their design process.

Author Contributions: Conceptualization, A.K.; methodology, A.K., M.B., C.S.; writing-original draft preparation, A.K.; writing-review and editing, C.S., M.B.; visualization, A.K., M.B.; supervision, C.S., M.B.; project funding acquisition, C.S., A.K.

Funding: This research was supported by funding from the Queen Elizabeth II Graduate Scholarships in Science and Technology, Ontario Graduate Scholarships, and the Yeates School of Graduate Studies.

Conflicts of Interest: The authors declare no conflict of interest.

\section{References}

1. Fletcher, K.; Grose, L.; Hawken, P. Fashion and Sustainability: Design for Change; Laurence King: London, UK, 2012; ISBN 9781856697545.

2. Hethorn, J.; Ulasewicz, C. Sustainable Fashion: Why Now; Fairchild: New York, NY, USA, 2008.

3. Niinimäki, K.; Hassi, L. Emerging design strategies in sustainable production and consumption of textiles and clothing. J. Clean. Prod. 2011, 19, 1876-1883. [CrossRef]

4. Karaosman, H.; Morales-Alonso, G.; Brun, A. From a systematic literature review to a classification framework: Sustainability integration in fashion operations. Sustainability 2016, 9, 30. [CrossRef]

5. Allwood, J.M.; Laursen, S.E.; de Rodriguez, C.M.; Bocken, N. Well Dressed? The Present and Future Sustainability of Clothing and Textiles in the United Kingdom; University of Cambridge Institute for Manufacturing: Cambridge, UK, 2006.

6. Fletcher, K. Sustainable Fashion E Textiles: Design Journeys; Earthscan: London, UK, 2008.

7. Gwilt, A.; Rissanen, T. Shaping Sustainable Fashion: Changing the Way We Make and Use Clothes; Earthscan: London, UK, 2011.

8. Krippendorff, K. The Semantic Turn: A New Foundation for Design; CRC Press: Boca Raton, FL, USA, 2006; ISBN 9780415322201.

9. Chapman, J. Prospect, seed and activate: Advancing design for sustainability in fashion. In Routledge Handbook of Sustainability and Fashion; Fletcher, K., Tham, M., Eds.; Routledge: New York, NY, USA, 2014; pp. 74-81.

10. Knight, P.; Jenkins, J.O. Adopting and applying eco-design techniques: A practitioners perspective. J. Clean. Prod. 2009, 17, 549-558. [CrossRef]

11. Madge, P. Design, ecology, technology: A historiographical review. J. Des. Hist. 1993, 6, 149-166. [CrossRef]

12. Papanek, V. Design for the Real World; Thames \& Hudson: London, UK, 1984; ISBN 0500231656.

13. Rawsthorn, A. Design as an Attitude; JRP Ringier: Zurich, Switzerland, 2018.

14. Niinimäki, K. Ecodesign and textiles. Res. J. Text. Appar. 2006, 10, 67-75. [CrossRef]

15. Ceschin, F.; Gaziulusoy, I. Evolution of design for sustainability: From product design to design for system innovations and transitions. Des. Stud. 2016, 47, 118-163. [CrossRef]

16. Sustainable Apparel Coalition Higg Materials Sustainability Index. Available online: https://msi.higg.org/ page/msi-home (accessed on 15 May 2018).

17. Vogtländer, J.G. Lca: A Practical Guide for Students, Designers and Business Managers; Delft Academic Press: Delft, The Netherlands, 2010.

18. Black, S.; Eckert, C. Considerate design: Supporting sustainable fashion design. In The Sustainable Fashion Handbook; Black, S., Ed.; Thames \& Hudson: London, UK, 2012; pp. 92-95.

19. Aakko, M.; Koskennurmi-Sivonen, R. Designing sustainable fashion: Possibilities and challenges. Res. J. Text. Appar. 2013, 17, 13-22. [CrossRef]

20. Jin Gam, H.; Cao, H.; Farr, C.; Heine, L. C2CAD: A sustainable apparel design and production model. Int. J. Cloth. Sci. Technol. 2009, 21, 166-179. [CrossRef]

21. LaBat, K.L.; Sokolowski, S.L. A three-stage design process applied to an industry-university textile product design project. Cloth. Text. Res. J. 1999, 17, 11-20. [CrossRef] 
22. May-Plumlee, T.; Little, T.J. No-interval coherently phased product development model for apparel. Int. J. Cloth. Sci. Technol. 1998, 10, 342-364. [CrossRef]

23. Cradle to Cradle Products Innovation Institute Cradle 2 Cradle Certified Products Program. Available online: https://www.c2ccertified.org/ (accessed on 1 May 2019).

24. Fashion for Good Fashion for Good. Available online: https://fashionforgood.com/ (accessed on 12 February 2019).

25. Made-By MODE Tracker. Available online: http://www.made-by.org/modetracker/ (accessed on 15 May 2018).

26. Centre for Sustainable Fashion Making:Nike. Available online: http://sustainable-fashion.com/projects/nike/ (accessed on 1 May 2019).

27. Nike Inc Making of Making by NIKE MSI. Available online: https://itunes.apple.com/us/app/making-makingpowered-by-nike/id662227880 (accessed on 1 May 2019).

28. Design School Kolding Approaches to Sustainable Design. Available online: https://sustainabledesigncards. $\mathrm{dk} /$ (accessed on 1 May 2019).

29. Hasling, K.M.; Ræbild, U. Sustainability Cards: Design for Longevity. In Proceedings of the Product Lifetimes and the Environment (PLATE 2017), Delft, The Netherlands, 8-10 November 2017; Bakker, C.A., Mugge, R., Eds.; Delft University of Technology: Delft, The Netherlands, 2017; pp. 166-170.

30. Hur, E.; Beverley, K.; Cassidy, T. Development of an ideation toolkit supporting sustainable fashion design and consumption. Res. J. Text. Appar. 2013, 17, 89-100. [CrossRef]

31. Gwilt, A. Exploring a framework for fashion design for sustainability. In Handbook of Sustainable Apparel Production; Muthu, S.S., Ed.; CRC Press: Boca Raton, FL, USA, 2015; pp. 439-452.

32. Textile Environment Design Ted's Ten. Available online: http://www.tedresearch.net/teds-ten-aims/ (accessed on 1 May 2019).

33. Harvey, L.; Green, D. Defining quality. Assess. Eval. High. Educ. 1993, 18, 9-34. [CrossRef]

34. Connor-Crabb, A.C. Fashion Design for Longevity: Design Strategies and Their Implementation in Practice. Ph.D. Thesis, University of Brighton, Brighton, UK, 2017.

35. Ræbild, U.; Hasling, K.M. Sustainable Design Cards: A Learning Tool for Supporting Sustainable Design Strategies. In Sustainable Fashion in a Circular Economy; Niinimäki, K., Ed.; Aalto University: Espoo, Finland, 2018; pp. 128-151.

36. Williams, D. Fashion Education in Sustainability: Change Through Experiential Crossings. 2013. Available online: http://ualresearchonline.arts.ac.uk/ (accessed on 1 May 2019).

37. Kozlowski, A.; Searcy, C.; Bardecki, M. The reDesign canvas: Fashion design as a tool for sustainability. J. Clean. Prod. 2018, 183, 194-207. [CrossRef]

38. Bovea, M.D.; Pérez-Belis, V. A taxonomy of ecodesign tools for integrating environmental requirements into the product design process. J. Clean. Prod. 2012, 20, 61-71. [CrossRef]

39. Lofthouse, V. Ecodesign tools for designers: Defining the requirements. J. Clean. Prod. 2006, 14, $1386-1395$. [CrossRef]

40. Hur, E.; Cassidy, T. Perceptions and attitudes towards sustainable fashion design: Challenges and opportunities for implementing sustainability in fashion. Int. J. Fash. Des. Technol. Educ. 2019, 12, 208-217. [CrossRef]

41. Palomo-Lovinski, N.; Hahn, K. Fashion Design Industry Impressions of Current Sustainable Practices. Fash. Pract. J. Des. Creat. Process. Fash. Ind. 2014, 6, 87-106. [CrossRef]

42. Brezet, H. Dynamics in ecodesign practice. UNEP Ind. Environ. 1997, 20, 21-24.

43. Mentz, S. After Sustainability. PMLA 2012, 127, 586-592. [CrossRef]

44. Harper, K. Aesthetic Sustainability: Product Design and Sustainable Usage; Routledge: Oxfordshire, UK, 2018.

45. Chapman, J. Emotionally Durable Design: Objects, Experiences and Empathy; Earthscan: London, UK, 2005; ISBN 184977109X.

46. Fletcher, K. Slow fashion: An invitation for systems change. Fash. Pract. J. Des. Creat. Process. Fash. Ind. 2010, 2, 259-266. [CrossRef]

47. Flood Heaton, R.; McDonagh, D. Can Timelessness through Prototypicality support sustainability? A strategy for product designers. Des. J. 2017, 20, S110-S121. [CrossRef]

48. Zafarmand, S.J.; Sugiyama, K.; Watanabe, M. Aesthetic and Sustainability: The aesthetic attributes promoting product sustainability. J. Sustain. Prod. Des. 2003, 3, 173-186. [CrossRef] 
49. Esslinger, H. Sustainable design: Beyond the innovation-driven business model. J. Prod. Innov. Manag. 2011, 28, 401-404. [CrossRef]

50. Atleo, E.R. Principles of Tsawalk: An Inigenous Approach to Global Crisis; UBC Press: Vancouver, BC, CA, 2011.

51. Štefko, R.; Steffek, V. Key Issues in slow fashion: Current challenges and future perspectives. Sustainability 2018, 10, 2270. [CrossRef]

52. Mora, E.; Rocamora, A.; Volonté, P. On the issue of sustainability in fashion studies. Int. J. Fash. Stud. 2014, 1, 139-147. [CrossRef]

53. Hu, Z.H.; Li, Q.; Chen, X.J.; Wang, Y.F. Sustainable rent-based closed-loop supply chain for fashion products. Sustainability 2014, 6, 7063-7088. [CrossRef]

54. Thorisdottir, T.S.; Johannsdottir, L. Sustainability within fashion business models: A systematic literature review. Sustainability 2019, 11, 2233. [CrossRef]

55. Balkenende, R.; Bakker, C. Designing for a Circular Economy: Make, Use and Recover Products. In Sustainable Fashion in a Circular Economy; Niinimäki, K., Ed.; Aalto University: Helsinki, Finland, 2018; pp. 76-95.

56. Manzini, E. Design, When Everybody Designs: An Introduction to Design for Social Innovation; MIT Press: Cambridge, MA, USA, 2015.

57. Ellen MacArthur Foundation. A New Textiles Economy: Redesigning Fashion's Future. Available online: http://www.ellenmacarthurfoundation.org/publications (accessed on 10 June 2018).

58. Minney, S. Slave to Fashion; New Internationalist Publications Ltd.: Oxford, UK, 2017.

59. Earley, R. Designing Fast \& Slow. Exploring fashion textile product lifecycle speeds with industry designers. Des. J. 2017, 20, S2645-S2656.

60. Ellen MacArthur Foundation. Artificial Intelligence and the Circular Economy-AI as a Tool to Accelerate the Transition. Available online: http://www.ellenmacarthurfoundation.org/publications (accessed on 1 May 2019).

61. Hsieh, H.-F.; Shannon, S.E. Three approaches to qualitative content analysis. Qual. Health Res. 2005, 15, 1277-1288. [CrossRef]

62. Wilkinson, L.; Friendly, M. The history of the cluster heat map. Am. Stat. 2009, 63, 179-184. [CrossRef]

63. Pousman, Z.; Stasko, J. A taxonomy of ambient information systems: Four patterns of design. In Proceedings of the Working Conference on Advanced Visual Interfaces-AVI '06, Venezia, Italy, 23-26 May 2006; pp. 67-74.

64. Wölfel, C.; Merritt, T. Method card design dimensions: A survey of card-based design tools. In Proceedings of the 14th IFIP TC 13 International Conference, Cape Town, South Africa, 2-6 September 2013; Kotźe, P., Ed.; Volume 8117 LNCS, pp. 479-486.

65. Guest, G.; McLellan, E. Distinguishing the trees from the forest. Field Methods 2003, 15, 186-201. [CrossRef] 